\title{
EL NEÓSTILO Y LAS PRIMERAS MANIFESTACIONES DE LA ILUSTRACIÓN EN NUEVA ESPAÑA*
}

\author{
MARTHA FERNÁNDEZ
}

\section{Introducción}

Se considera -y yo misma lo creo así- que el movimiento artístico que respondió plenamente a los requerimientos racionalistas de la Ilustración fue el neoclásico. Estilo que volvió a apegarse a los viejos cánones de los tratadistas, que se inspiró a menudo en modelos franceses y que pretendió ser, precisamente, un arte racional ${ }^{1}$

Una real cédula expedida por Carlos III y fechada el 25 de diciembre de $1783^{2}$ convirtió al neoclásico en la estética moderna de la Nueva España: “.... lúcida, alegre, bella porque admiraba lo regular, lo espacioso, la sencillez, el adorno moderado, lo grande, la unidad, lo razonable, lo magnífico, la pureza de estilo"."

La Real Academia de las Tres Nobles Artes de San Carlos de la Nueva España, que promoviera el grabador Gerónimo Antonio Gil y que abriera sus puertas en $1781,{ }^{4}$ tuvo “...una decidida dirección didáctica y encauzadora del gusto general". ${ }^{5}$

Pero si bien el neoclásico puede ser calificado como el exponente artístico más representativo de la Ilustración, no fue el único. En esta ocasión,

\footnotetext{
"Agradezco a los maestros Jorge Alberto Manrique y Roberto Moreno sus acertados comentarios a este texto. Esta investigación fue presentada como ponencia en el II Simposio Internacional de Arte Barroco Iberoamericano, celebrado del 26 de julio al 1o de agosto de 1991 en la ciudad de Querétaro; organizado por la Secretaría de Relaciones Exterior es, el Instituto Nacional de Bellas Artes, el Consejo Nacional para la Cultura y las Artes, el Ayuntamiento de Querétaro, la Asociación de Industriales de Querétaro, la Asociación de Amigos de la Catedral Metropolitana y el Museo Franz Mayer.

'Jorge Alberto Manrique: "Del barroco a la Ilustración", en Historia General de México, t. I, 3a ed, México, El Colegio de México, 1981, p.734.

${ }^{2}$ Eduardo Báez Macías: Fundacióne historia de la Academia de San Carlos, México, Departamento del Distrito Federal, Secretaría de Obras y Servicios, 1974 (Colección Popular, Ciudad de México: 7), p. 20 .

${ }^{3}$ Justino Fernández: El Retablo de los Reyes. Estética del Arte Mexicano, 2a ed, México, Universidad Nacional Autonóma de México, Instituto de Investigaciones Estéticas, 1990 (Estudios de Arte y Estética), p.220

${ }^{4}$ Eduardo Báez Macías." op.cit., p 18.

${ }^{5}$ Jorge Alberto Manrique: op.cit., p. 733.
} 
pretendo hacer notar la presencia de las luces en un conjunto de monumentos barrocos que fueron definidos y bautizados por Jorge Alberto Manrique con el nombre de neóstilo. ${ }^{6}$

Para tratar de hacerme entender en esta aventura, recordaré brevemente algunas de las características más importantes de la Ilustración novohispana.

\section{La Ilustración en la Nueva España}

De acuerdo con algunos especialistas como Roberto Moreno, entre los rasgos más sobresalientes que poseyó la Ilustración en la Nueva España se pueden enumerar los siguientes: interés por "... mostrar al mundo los valores americanos, y novohispanos en particular; esfuerzo por introducir las ciencias modernas en estas tierras y... estudiar el pasado prehispánico y registrar los avances de los pueblos indigenas".

Lo más importante es que todo ello se realizó con una actitud muy diferente a la adoptada en los siglos Xvi y xvi: en aquel momento, se aceptaban como buenos y se exhibían con el orgullo y la seguridad de la "grandeza mexicana" todos los valores de la cultura local, por medio de exaltadas apologías, cuya intención no fue otra que vanagloriarse de lo propio. ${ }^{8}$

Durante el siglo xvir (en especial a partir de 1740-50), lo que encontramos, en cambio, es una actitud crítica frente a la realidad, que se manifestó de dos maneras. Por un lado, el interés de los novohispanos por llevar a cabo "inventarios o recuentos" de sus riquezas materiales y espirituales, tanto prehispánicas como virreinales.

En opinión de Luis González, el objetivo de tales inventarios fue impugnar las teorías antiamericanistas "... por amor a la patria...", pero utilizando ya como instrumentos ".... el racionalismo moderno y el humanismo de los colegios jesuíticos de México...". 9

Con este espíritu, no apologético, sino crítico, deben entenderse obras como la Historia Antigua de México de Francisco Javier Clavijero, la Historia

${ }^{6}$ Jorge Alber to Manrique: "El 'neóstilo': la última carta del barroco mexicano", en Historia Mexicana, El Colegio de México, 79 (México, enero-marzo de 1971), pp.335-367

${ }^{7}$ Rober to Moreno: "Ensayo bibliográfico de Antonio León y Gama", en Boletín del Instituto de Investigaciones Bibliográficas, Universidad Nacional Autonóma de México, t. II, núm. 1 (México, enero-junio de 1970), p.44.

${ }^{8}$ Acerca de la cultura y el pensamiento criollos véase: Edmundo O'Gorman: Meditaciones sobre el criollismo. Discurso de ingreso en la Academia Mexicana Correspondiente de la Española, México, Centro de Estudios de Historia de México, Condumex, 1970

${ }^{9}$ Luis González y González: "El optimismo nacionalista como factor de la Independencia de México", en Estudios de Historiografía Americana, México, El Colegio de México, 1948, p. 163 
civily política de México del padre Andrés Cavo y los elogiosos "Prólogos" de la cultura novohispana escritos por Juan José Eguiara y Eguren en su Biblioteca Mexicana, por citar sólo unos cuantos ejemplos.

Por otro lado, ese espíritu crítico también se encontró en quienes, como explica Jorge Alberto Manrique, “...dejaron de ver con beneplácito la realidad mexicana..." ${ }^{" 10}$ y se presentó en ellos una concientización no de las virtudes, sino de los defectos y problemas que se tenían que erradicar de la vida de la Nueva España. Tal sería el caso de fray José Joaquín Granados, quien en sus Tardes Americanas concibió la etapa virreinal como un oscuro paréntisis destructor del esplendor del pasado prehispánico, y fray Agustín de Morfi, quien en su Viaje de indios y diario del Nuevo Mundo muestra su claro disgusto por el arte barroco.

En ambas posturas queda claro que, como bien afirma Roberto Moreno, la Ilustración debe entenderse en realidad como "...un complejo de ideas y prácticas y no sólo como un sistema filosófico..."..1

Veamos entonces cómo estas ideas y prácticas tomaron forma y las podemos encontrar dentro del arte barroco.

\section{Las luces dentro del barroco}

Para comprender la razón de ser que en lo personal atribuyo al neóstilo, comenzaré por analizar -aunque sea de modo general-dos de las primeras manifestaciones de una actitud que yo califico de ilustrada en los arquitectos barrocos: las reformas a las Ordenanzas, que propusieron los maestros el año de 1746, y un tratado novohispano de arquitectura barroca, escrito en la segunda mitad del siglo XVIII.

\section{a) Las reformas a las Ordenanzas de Albañilería}

En cuanto a las reformas de las Ordenanzas, lo primero que debe destacarse es que el solo planteamiento de una "reforma" implica el reconocimiento de que algo está mal y debe cambiarse, lo cual nos conduce a pensar, por lo menos, en una racionalización de los problemas, en un cambio de mentali-

${ }^{10}$ Jorge Alberto Manrique: "Del barroco a la Ilustración", p 732. Jorge Alberto Manrique: "El pesimismo como factor de la Independencia de México", en Conciencia y autenticidad históricas. Escritos en homenaje a Edmundo O'Gorman, México, Univer sidad Nacional Autónoma de México, 1968, pp. 177-196.

${ }^{11}$ Roberto Moreno: op.cit., p. 43. 
dad, como lo es el hecho de que no hayan sido las autoridades, sino el propio gremio, quien haya observado la necesidad de modificar las cosas.

Así, el 25 de abril de 1746, los maestros Miguel Custodio Durán y Lorenzo Rodríguez -veedores del gremio-; Miguel Espinosa de los Monteros -maestro mayor de la Catedral y Real Palacio de México-; José Eduardo de Herrera-obrero mayor del Santo Oficio-; Manuel Álvarez-maestro mayor de la ciudad de México-; José de Roa, Bernardino de Orduña, José Antonio González e Ildefonso de Iniesta Bejarano, elaboraron el documento tendente a reformar las Ordenanzas de Albañilería que los habían regido desde el siglo xv, y que presentaron ante el Cabildo de la Ciudad el 26 de abril del mismo año $1746 .^{12}$

Los arquitectos reformistas eran barrocos, asílo demuestran en sus obras; sin embargo, su reacción frente a su situación como artistas resultó completamente crítica. Su primera objeción a las viejas Ordenanzas es muy interesante. A la letra dice: "Reconocidas las Reales Ordenanzas, en varias partes de ellas tiene la palabra Albañilería, y siendo Arte de Arquitectura, deberá intitularse así y tildarse Albañilexía." 13

Con esto señalaban "...la jerarquía y conciencia de una categoría profesional diferente y superior a la de albañil, ya que los arquitectos no sólo ejecutaban, sino también proyectaban, y querían significar ese rango..." y elevar el aprecio de su quehacer a nivel de arte, por supuesto, en cuanto bello y racional. ${ }^{14}$

Tanto es así, que en el tratado novohispano de arquitectura, que analizaremos después, se afirma que

Architectura civil es una ciencia que enseña aplantar y edificar con firmeza, proporción y hermosura; Sus profesores aunque regularmente se equibocan con los nombres de Architectos, Alarifes, y Maestros Mayores, por estrecha y rigorosamente se deven llamar Architectos y Maestros Mayores de tal... ${ }^{15}$

Esto queda demostrado al analizar el uso que se dio al término "arquitectura"

\footnotetext{
${ }^{12}$ Martha Fernández: Arquitectura y gobierno virreinal Los maestros mayores de la ciudad de México Siglo xVI, México, Universidad Nacional Autónoma de México, Instituto de Investigaciones Estéticas, 1985 (Estudios y Fuentes del Arte en México:XLV), pp. 31-32, 29.3-295; apud: AACdM (Arquitectos: 380 , doc. 1, fol. 34 x.-35 vto.).

${ }^{13}$ Ibidem, p. 293; apud: AACdM (Arquitectos: 380, doc 1, fol 34r..-35 vto.)

${ }^{14}$ Ibidem, p. 32.

${ }^{15}$ Mardith K. Shuetz: Architectural practice in Mexico City. A Manual for Jumeyman Architects of the Eighteenth Century, Tucson, The University of Arizona Press, 1987, p.113. La versión paleográfica de la editora fue respetada íntegramente en todas las citas del tratado por no contar con ningún ejemplar del manuscrito original que me permitiera cotejar la transcripción.
} 
a lo largo de la época virreinal. Tal vocablo comenzó a emplearse en la Nueva España a partir del siglo xvi y se utilizó indistintamente al lado de los de "alarife" " "maestro de albañilería" para designar a los maestros examinados. Por lo tanto, tampoco existió diferenciación en el tipo de trabajo que desarrollaban: sin importar el término con el que fueran nombrados, todos valuaban, todos construían y todos proyectaban. ${ }^{16}$

A partir de las reformas a las Ordenanzas propuestas por los arquitectos en 1746, el término "arquitectura" comenzó a adquirir mayor importancia y una connotación relacionada con los conocimientos del maestro y con su nivel de artista. ${ }^{17}$ De esta manera, de ser "arquitectos", "maestros de arquitectura" y "maestros del arte de arquitectura", los maestros pasan a serlo "en el Nobilísimo Arte de Arquitectura", como se mencionan, por ejemplo, a Diego José Dávila y Chávez en 1748, y a José Cayetano de Sigüenza en 1752 y $1770 .{ }^{18}$

Es entonces cuando se establecen diferencias en cuanto al grado de conocimientos entre un albañil (como la mano de obra en las construcciones) y los alarifes y arquitectos, que eran los tracistas y directores de las obras. Prueba de ello es que en el tratado novohispano de aquitectura, se concluye que

El Architecto, según el sentido rigoroso de la Ley, es el Principe de los Edificios, o fabricas, llamase Principe, o principal, por ser el principal edificador, que de las plantillas de los Arcos Bobedas etc. No es menester que sea de profession Albañil, como quieren algunos: basta que sea practico, en la Architectura, Montea y Cortes de canteria y que pueda rayar qualquier genero de Arco, o de buelta. ${ }^{19}$

Aunque el tratado es un poco posterior a las propuestas de reforma que analizamos, nos muestra claramente la importancia que tuvo para los maestros cambiar el título de las Ordenanzas: los arquitectos eran los que tenían los conocimientos suficientes para desartollar su trabajo a nivel artístico.

Además de modificaciones, los arquitectos propusieron también que se añadieran nuevas ordenanzas a las ya existentes; entre ellas, la que vendría a ocupar el número 18 interesa especialmente, pues plantea la posibilidad de establecer una paga de derechos a los maestros por la tasación de las obras,

\footnotetext{
${ }^{16}$ Martha Fernández: "El albañil, el arquitecto y el alarife en la Nueva España", en Anales del Instituto de Investigaciones Estéticas, 55 (México, 1986), pp. 49-68.

${ }^{17}$ Idem.

${ }^{18}$ Ibidem, p. 61; apud: Glorinela González Franco, Ana Eugenia Reyes y Cabañas y Angelina Olivas Vargas: "Notas para una guía de artistas y artesanos de la Nueva España I", en Boletín Monumentos Histôricos, I (México, 1979), basadas en AGN (Bienes Nacionales: 85, doc. 21).

${ }^{19}$ Mardith K. Shuetz: op.cit., pp. 113-114.
} 
disponiendo que se habría de cobrar un tanto por ciento del total de lo valuado

.... por deberse atender como honorario al trabajo teórico y práctico que tenemos, no sólo en las medidas y reconocimientos de sitios, paredes, techos, puertas, ventanas, envigados y demás menudencias de que se componen las fábricas, para lo cual es necesario formar varias cuentas y haber trabajado antes mucho para tener la inteligencia necesaria del valor de cada cosa ${ }^{20}$

En este sentido, resulta importante el hecho de que “...se haya iniciado la preocupación por el trabajo remunerado como justo y meritorio para una actividad artística, según los arquitectos de la época consideraban su quehacer...". ${ }^{21}$ No es que antes no cobraran los avalúos que llevaban a cabo; lo que ocurre es que al plantearlo como una inquietud a nivel gremial, se pretendió precisamente darle el valor que realmente merecía al trabajo artístico en conjunto.

Por otra parte, intentaron cobrar por el trabajo concreto de un avalúo, pero también, y esto es lo más importante, por el "trabajo téorico" y la "inteligencia necesaria del valor de cada cosa", es decir, por sus conocimientos.

Las reformas a las Ordenanzas nunca fueron aprobadas; de hecho, el 9 de septiembre de 1754 se publicaron de nuevo las viejas Ordenanzas de 1599, ${ }^{22}$ pero el breve análisis que he llevado a cabo de dos de los puntos propuestos para ser modificados nos indica que los planteamientos de los problemas y las soluciones ofrecidas reflejan una mentalidad más crítica, más analítica, en la cual se concede importancia a cuestiones como los conocimientos, que no podemos explicar si no aceptamos la penetración de las ideas ilustradas en el ámbito propiamente barroco, aun antes del establecimiento de la Academia de San Carlos. Para confirmarlo, de nuevo una cita del tratado novohispano de arquitectura: "La Escultura, Pintura y Architectura, son las tres bellas Artes, en Virtud de las que en París, y en toda España a su título se ordenan." 23

${ }^{20}$ Martha Fernández: Arquitectura y gobierno virreinal.., pp. 34, 294-295; apud: AACdM (Arquitectos: 380 , doc 1 , fol $34 \mathrm{r}_{-}-35$ vto.).

${ }^{21}$ Ibidem, pp. 34-35

22 Ibidem, p. 42; apud: AACdM (Arquitectos: 380, doc 1 fol 54r- 54 vto.). Las primeras Ordenanzas de Albañileria fucron expedidas por el Cabildo Justicia y Regimiento de la ciudad de México el 27 de mayo de 1599 y confirmadas por el virrey conde de Monterrey el 30 de agosto de ese mismo año

${ }^{23}$ Mardith K Shuetz: op.cit, p. 97. 


\section{b) Architectura Mecanica conforme a la practica de esta ciudad de Mexico}

El tratado al que nos hemos venido refiriendo se titula Architectura Mecanica conforme a la practica de esta ciudad de Mexico. Se desconoce la fecha en que fue escrito, así como el nombre de su autor.

De acuerdo con Mardith K. Shuetz, editora del tratado, éste debió haberse escrito entre 1794 y $1813 ;{ }^{24}$ no obstante, las referencias que se encuentran en el texto a escritos, mapas y personajes que no rebasan el año de 1760, así como la ausencia total de una mención, siquiera mínima, a la Academia de San Carlos, nos indican claramente que el tratado debió redactarse antes de 1781. En cuanto al autor, a reserva de reconocer que falta un estudio más profundo del tratado, puede afirmarse, de entrada, que se trata de un arquitecto barroco. ${ }^{25}$

El hecho de reconocer en este libro su carácter de tratado nos lleva a la consideración de que nos encontramos frente a un texto ilustrado. Los tratados son el instrumento mediante el cual se ordenan y se codifican los conocimientos de una determinada materia para su correcta aplicación. Ésta, que resulta una antiquísima práctica, durante el siglo xvir se retomó gracias, como explica Juana Gutiérrez, al nacimiento de “.. la Estética y de la teorización que de los elementos artísticos se hizo. La ilustración pasó de la práctica a los modelos y a las normas, y de ahí a la abstracción teórica" " ${ }^{26}$

Además, por obvias razones, los tratados poseen ese espíritu de "inventario o recuento" analítico propio de las manifestaciones ilustradas, tal como vimos anteriormente, respecto a otras áreas del conocimiento.

Los temas que abarca la Architectura Mecanica son variados: la correcta pronunciación, definición y etimología de algunos términos utilizados por los arquitectos de la época; ${ }^{27}$ los libros, instrumentos y mapas más recomendables (como los tratados de los padres fray Lorenzo de San Nicolás y fray Vicente Tosca, así como el Mapa de la América Septentrional de José Antonio de

${ }^{24}$ Ibidem, p 23

${ }^{25}$ En mi opinión, el autor del tratado debió haber sido un maestro mayor; por lo tanto, creo que puede considerarse el nombre de Lorenzo Rodríguez, lo cual no resultaría extraño después de que este maestro formó partẹ de los arquitectos que pretendieron reformar las Ordenanzas en 1746. La Dra. Clara Bargellini, investigadora del Instituto de Investigaciones Estéticas de la Universidad Nacional Autónoma de México, prepara un estudio sobre este tratado.

${ }^{26}$ Juana Gutiér rez: "El Arte de la Ilustración en México", inédito Agradezco a la autora el ejemplar del maquinuscrito que me facilitó para elaborar esta ponencia

${ }^{27}$ Mardith K. Shuetz: op cit, pp. 86, 88, 91, 93, 98, 99, 115, 116 
Villaseñor y Sánchez)..$^{28}$ Elabora algunas normas para resolver problemas técnicos concretos (como la "Regla para hacer varas cúbicas de una Pared", el "Método de tirar una Pared sin que se caiga la de arriba que carga sobre la que se ade tirar", el "Methodo y practica para hazer una Tazazion"). ${ }^{29}$

Entre las explicaciones más significativas que contiene este tratado se encuentra la manera de levantar una portada barroca y lo hace con las siguientes palabras:

Llaman obras de Talla a las portadas que ahora están usando, y verdaderamente no vienen a ser otra cosa que unos colaterales en la calle. El orden que ha de aguardar el Architecto hade ser el siguiente. La planta de una portada bien lo puede hacer qualquier pintor siendo diestro, pero este hade ser bajo aquel repartimiento que le diere el Maestro Verbigratia los tamaños que le corresponden al primero segundo cuerpo etc. Mejor juzgue que dicha planta o como otros dizen al alzado lo haya de sacar un Maestro de Ensamblador. Ensambladores son aquellos artífices de colaterales: Dicese pues que estos saven mui bien lo que es alzado, y las molduras que pueden entrar las boladas, y prosecturas quanto hande tener en todo lo demas que deve registrar, y corregir el Architecto antes de comenzar la obra, por que si save dibujar, vista la planta que le trae el Ensamblador. Veera si es agradable a la Vista y si tiene algunos defectos que corregir verbigratia que le falte proporcion a la Cornisa, que los pedestales se reduzgan a aquel orden que deven tener por que ya se veé que es importante que cargue lo cano sobre lo Diorico y otras cosas a este tener: corregida la planta, y haviendo salido a toda su contemplacion, llamara a los talladores sobre piedra y con el capataz de los canteros conferira todo lo combeniente para dar principio asu obra que esten travajando arreglados ala planta de perspectiva, e ichonografica sin exeder los limites de lo que ha mandado el maestro ${ }^{30}$

Resulta entonces claro que el autor del tratado Architectura Mecanica era barroco, pero su época lo llevó a concebir su quehacer como un arte, lo racionalizó y buscó la forma de marcar lineamientos, modos de hacer y ejercer con corrección, que ya sistematizados organizó en este libro, para efectivamente elevar su trabajo a ese nivel.

Éstas son, pues, algunas de las manifestaciones que muestran la presencia de la llustración en el ámbito barroco, que nos indican que los arquitectos

${ }^{28}$ Ibidem, pp. 102-104. Los tratados de fray Lorenzo de San Nicolás se titulan Arte y uso de Architectura y Segunda parte del Arte y uso de Architectura. El de Tomás Vicente Tosca: Compendio Mathemático, en que se contienen todas las materias más principales de las ciencias que trata de la Cantidad. Tomo V. Que comprhende Arquitectura Militar, Pirotechnia y Artillería.

${ }^{29} \mathrm{Ibidem}$, pp. 91, 92, 93, 95

${ }^{30}$ Ibidem, pp.98-99. 
barrocos no sólo no fueron ajenos a las ideas ilustradas, sino que incluso las pusieron en práctica dentro de su propia tradición.

Lo que corresponde ahora es deslindar lo que de Ilustración posee el neóstilo.

\section{El neóstilo}

Como afirmé al principio, este término fue acuñado por Jorge Alberto Manrique para bautizar una "...modalidad del barroco mexicano, que corresponde al último momento de ese arte....".

Su característica más importante es el rescate que llevó a cabo de la columna (de ahí su nombre) y de la pilastra (no estípite). Pero gracias a la forma en que retomó esos elementos, los convirtió en algo nuevo y diferente, por lo que el autor citado considera a esa "....vigorosa y rica reacción barroca como una nueva época de la columna, o la época de la nueva columna...". ${ }^{32}$

Para llegar a esa transformación, el neóstilo utilizó dos instrumentos: las viejas formas de la tradición barroca novohispana y las dotó de nuevo sentido, al mismo tiempo que empleó recursos nuevos.

Por su tarea de recopilación, Manrique concede al neóstilo "...una especie de 'nueva conciencia', un sentido de revisión". ${ }^{33}$ En su repertorio aparecen los más famosos y significativos artificios utilizados por el arte barroco a lo largo de su existencia. Apoyos como las columnas clásicas de fuste liso (como en el templo de San Lorenzo), con estrías rigzagueantes u ondulantes (como en el templo de la Enseñanza), columnas salomónicas (como en la parroquia de Santa Prisca de Taxco), pilastras ornamentadas (como en el palacio de los condes de Heras Soto) y pilastras salomónicas (como en las portadas laterales de la capilla del Pocito). ${ }^{34}$

Pero también reutilizó el interestípite, el almohadillado mixtilíneo, la guardamalleta, follajes propios del barroco salomónico, tallas características del barroco estípite, ornamentación rococó, etcétera. ${ }^{35}$

En esta tarea de rescate, fue asimismo importante la nueva revisión de los tratados ${ }^{36}$ Ya hemos visto que en la Architectura Mecanica se mencionan los que a juicio del autor resultan los mejores y por ello no extraña que, por ejemplo,

\footnotetext{
${ }^{31}$ Jorge Alberto Manrique: "El 'neóstilo': la última carta del barroco mexicano", op.cit., 335.

${ }^{32}$ Ibidem, p. 345

${ }^{33} \mathrm{Ibidem}$, p. 362

${ }^{34}$ Ibidem, pp. $349-356$.

${ }^{35}$ Ibidem, pp. 356-358.

${ }^{36}$ Ibidem, p. 362.
} 
la capilla del Pocito (por citar el caso más conocido) haya estado inspirada por una antigua planta romana publicada por Serlio, pero claro está, imprimiéndole siempre sentido barroco.

Ahora bien, el neóstilo retomó formas, recursos y artificios anteriores, pero he dicho -repitiendo a Manrique- que lo hace con un nuevo sentido y a veces llegó más lejos que sus modelos. Tal audacia la consiguió gracias a que ésta resultó ser una modalidad más informada que sus antecesoras y, por lo tanto, más consciente de las posibilidades del barroco, por lo que pudo reforzar precisamente el barroquismo de las obras.

Tal vez el elemento que pudiera servirnos para ejemplificar de la mejor manera esa idea sea la columna salomónica. En la mayoría de los ejemplos del siglo xvi (por lo menos de la ciudad de México), las columnas salomónicas están recorridas por una guía ornamental que da la impresión de ser ella la que “... 'oprime' el fuste... y altera su rectitud." ${ }^{37}$ Así se encuentran, por ejemplo, en el templo de Santa Teresa la Antigua y en los nichos de las portadas de San Bernardo. Las del imafronte de la Catedral de México y las de la portada principal del templo de San Agustín poseen un helicoide un poco más amplio, pero no se olvida la guía ornamental, ni los senos achaflanados, que restringen el vuelo de las columnas.

No podemos ocuparnos de las variadas intepretaciones que se dio a "lo salomónico" y que llegó incluso a las columnas de fuste ondulante (como las de la portada principal del templo de San Cristóbal de Puebla) ${ }_{9}^{38}$ pero -salvo quizá alguna excepción - las columnas salomónicas anteriores al neóstilo tendieron a ser tímidas en mostrar sus gargantas, y su fuste fue en general ancho y ornamentado.

En el neóstilo, en cambio, como comenta Manrique, encontramos “...un fuste helicoidal pero totalmente desnudo... el fuste mismo siempre es muy delgado y las roscas en que se retuerce están muy separadas entre sí...." ${ }^{39}$ Aunque, como en el caso de la iglesia de Santiago Tianguistengo, luzcan estrías en el primer tercio, su helicoide es muy amplio y pronunciado, por lo tanto, dan la impresión de ser columnas salomónicas más ortodoxas, más cuidadosas y más informadas.

Amén de la revisión que llevó a cabo, bajo las características que hemos visto, el neóstilo también fue -como he dicho-renovador y, en consecuen-

${ }^{37}$ Ibidem, p. 352.

${ }^{38}$ Respecto a las variadas interpretaciones que en mi opinión se dieron al barroco salomónico, puede verse, entre otros: Martha Fernández: Artificios del barroco. México y Puebla en el siglo XVII, México, Universidad Nacional Autónoma de México, Coordinación de Humanidades (Colección de Arte: 44).

${ }^{39}$ Jorge Alber to Manrique: "El 'neóstilo': la última carta del barroco mexicano", op, citt, 353. 
cia "...inventó elementos o estructuras que no tienen antecedente directo en nuestro país" ${ }^{40}$ Jorge Alberto Manrique menciona tres: “...el atrevidísimo uso que hace de las molduras", ${ }^{41}$ el haber llegado a romper finalmente "...la estructura rígida de las fachadas y retablos reticulados" ${ }^{2} \mathrm{de}$ antecedente manierista, y la "...búsqueda que emprendió por conseguir ambientes diferentes arquitectónicamente", ${ }^{43}$ es decir, el empleo de plantas barrocas.

De ellos, los dos últimos resultan de capital importancia. Recordemos que desde el manierismo se mantuvieron sin alteración, tanto las portadas divididas esquemáticamente en calles y cuerpos, como los espacios rectilíneos de los edificios.

En cuanto a las portadas, con el neóstilo

...se pierde definitivamente respeto a aquella retícula de origen clásico, se rompe, agranda, descoyunta la calle central, se altera el ritmo de intercolumnios, las cornisas se desvanecen, los vanos irrumpen despiadadamente violentando la serenidad de otros elementos arquitectónicos. Se produce un caos y simultáneamente un nuevo orden en la arquitectura mexicana ${ }^{44}$

Así de ricas son las portadas de monumentos como el templo de la Enseñanza, Santa Prisca y Santiago Tianguistengo. Como bien afirma Manrique, "este solo hecho sería bastante para dar un lugar de excepción al barroco neóstilo", pero todavía va más lejos y emplea plantas y alzados a los que

....trata de sacar partido "barroco", en el sentido de las experiencias italianas y austriacas: consiguiendo efectos teatrales de iluminación, buscando sorprender y atraer al espectador por medio de los espacios arquitectónicos, usando no nada más los recursos decorativos del estilo, como hasta entonces se había hecho... inventa plantas novedosas y sorprendentes, que quiebra muros, que da iluminaciones inusitadas a sus interiores, que busca también soluciones nunca antes usadas aquí a la silueta de sus alzados....5

Tales son los casos de la ya mencionada capilla del Pocito y del templo de la Enseñanza de México, y no podemos olvidar la planta en forma de estrella

\footnotetext{
${ }^{40}$ Ibidem, p. 356

${ }^{41}$ Ibidem, p. 359

${ }^{42}$ Ibidem, pp. 359-360.

${ }^{43}$ Ibidem, pp 360-361.

${ }^{44}$ Ibidem, p. 360 .

${ }^{45}$ Ibidem, p. 361
} 
del hospital de Belén de Guadalajara. Ese fue también el momento en que se cambió la concepción del espacio en las iglesias de los conventos de monjas: del viejo cajón con portadas pareadas al eje de la nave (como en Santa Teresa la Antigua) se llega a templos con una sola portada al eje del presbiterio (como en la Enseñanza y en San Lorenzo).

La razón de existir del neóstilo la explica Jorge Alberto Manrique como "....un esfuerzo extremo por mantener la vigencia de un estilo que durante un siglo y medio había sido la expresión natural y plena de la Nueva España" " ${ }^{46}$ De acuerdo con el autor, el neóstilo "....dio lo que podríamos llamar 'la batalla del barroco'... con la bandera de la 'conciencia': frente a la inconciencia de seguir trabajando por los mismos caminos que había trazado el barroco estípite ....". ${ }^{47}$

Por supuesto, la modalidad queda inscrita dentro del "...espíritu de apertura y de reformismo, que intenta sacudir una cultura..." que hacia el tercer tercio del siglo xviı ya parecía "....como mortecina...". Tal reformismo coincidía con el reinado de Carlos III; sin embargo, en opinión de Manrique, ese movimiento

...no tiene nada que ver con la Ilustración posterior, negadora de toda la cultura propia: en el caso que trato [el neóstilo], se intenta abrir puertas y sacudir situaciones, pero no se quiere negar totalmente la cultura de los mayores, sino aprovecharla en la forja de algo nuevo. ${ }^{48}$

Debo aclarar que, para Jorge Alberto Manrique, puede de hecho establecerse una diferencia entre las "reformas borbónicas", entendidas " "... sobre todo como un 'mejoramiento', como un paso hacia adelante..." y la "modernidad de los ilustrados", que "...implicaba no un mejoramiento, sino un vuelco completo de la situación...no dar un pequeño tirón hacia adelante, sino trastocar las cosas completamente para poder implantar algo nuevo, en donde la experiencia anterior estuviera completamente desterrada, en donde no contara absolutamente para nada $\ldots . .,{ }^{49}$

Por lo tanto, para Manrique, los verdaderos ilustrados fueron los que manifestaron su actitud crítica poniendo énfasis en todos los aspectos negativos de la sociedad y la cultura novohispanas, los que definitivamente vieron "...con malos ojos la estructura social, la estructura administrativa, las

${ }^{46}$ Ibidem, p. 335.

${ }^{47}$ Ibidem, pp. 361-362.

${ }^{48}$ Ibidem, pp. 366-367.

${ }^{49}$ Jorge Alberto Manrique: "El pesimismo como factor de la Independencia de México", op. cit, pp. 190-191. 
DOI: http://dx.doi.org/10.22201/iie.18703062e.1993.64.1666

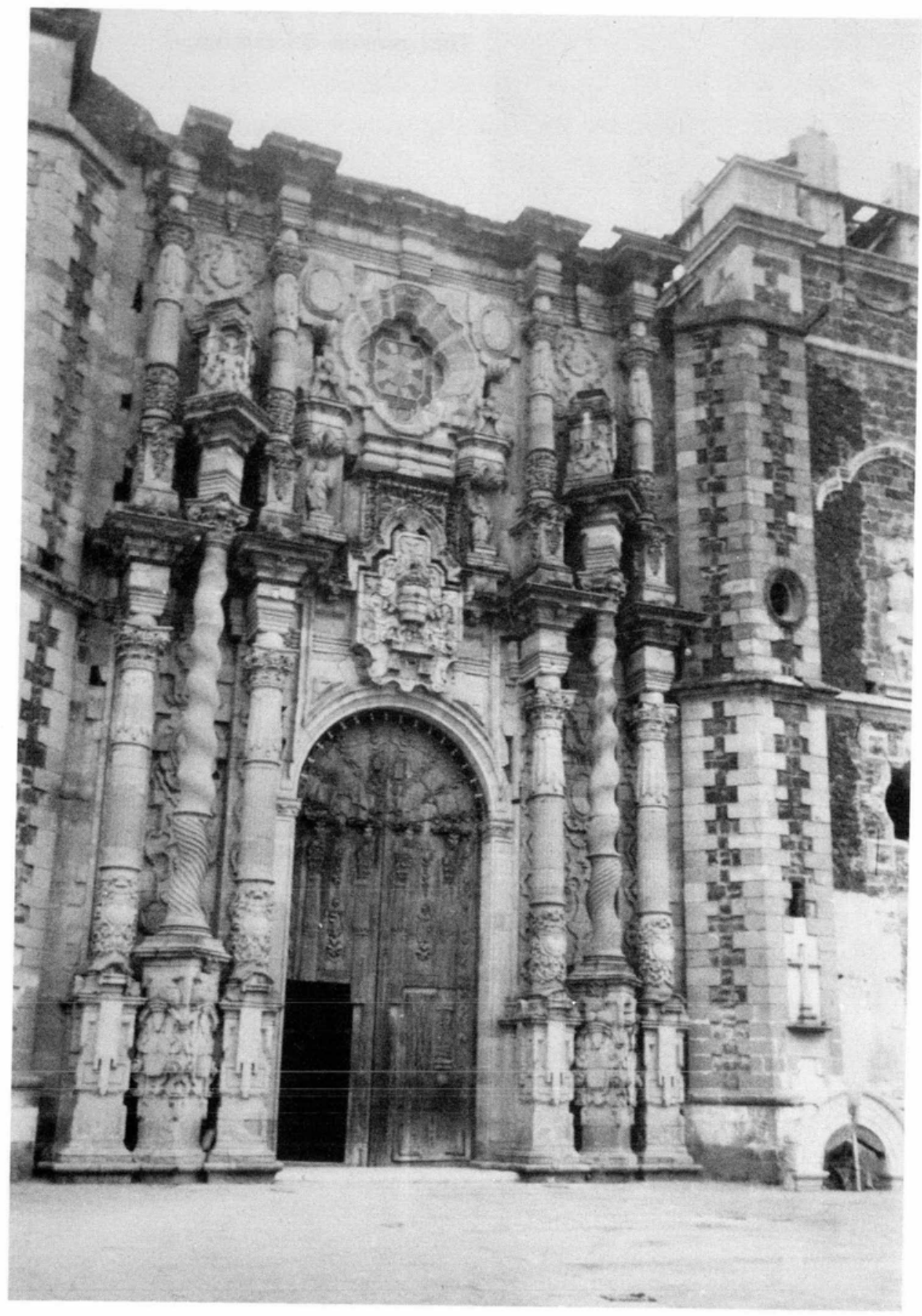

1. Templo de Santiago Tianguistengo. Portada. 


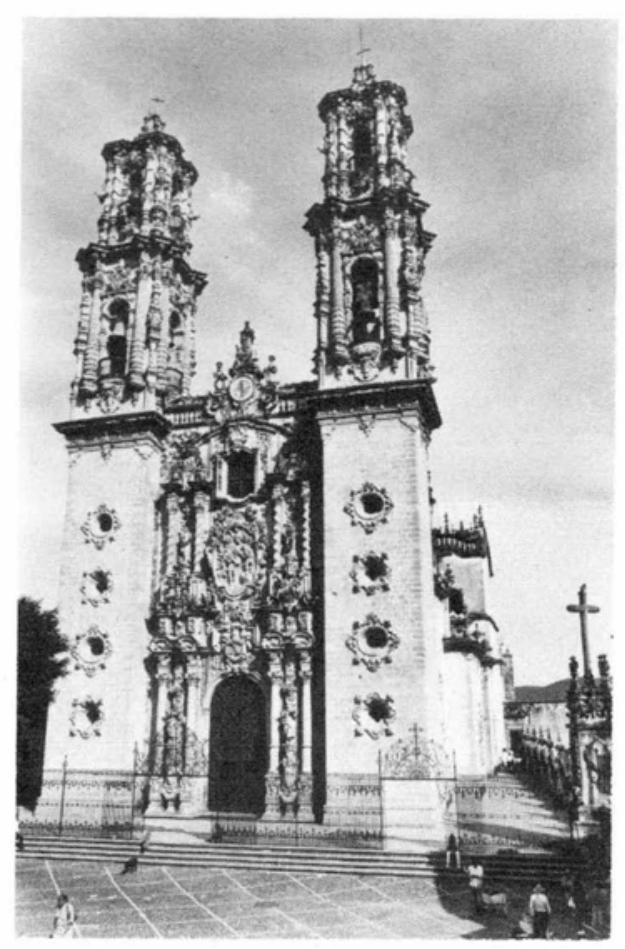

2. Parroquia de Santa Prisca de Taxco. Vista general del exterior.

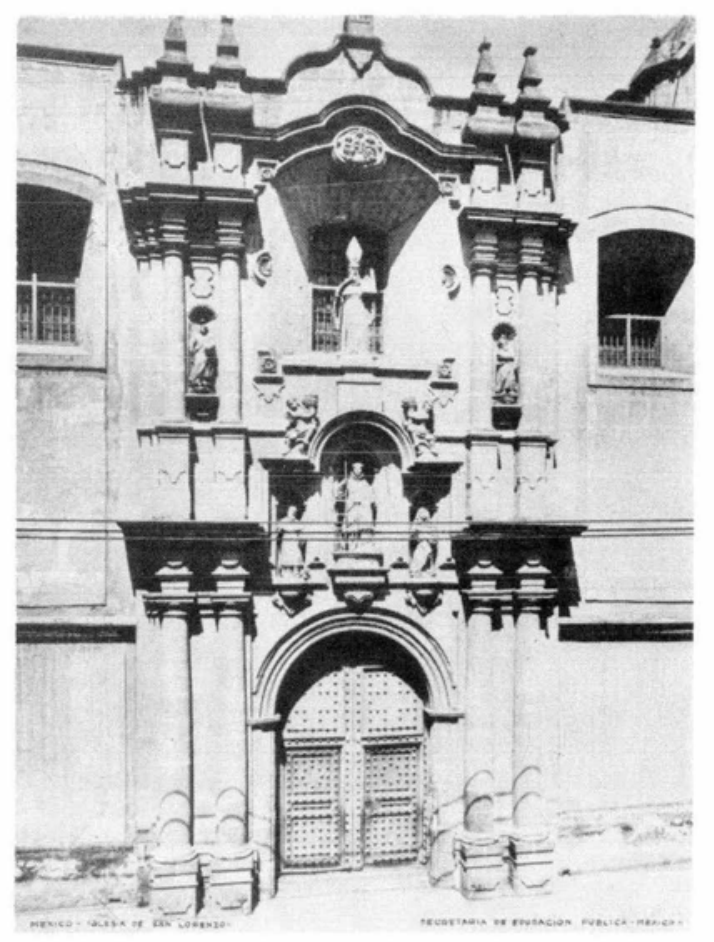

3. Templo de San Lorenzo. Ciudad de México. Portada. 


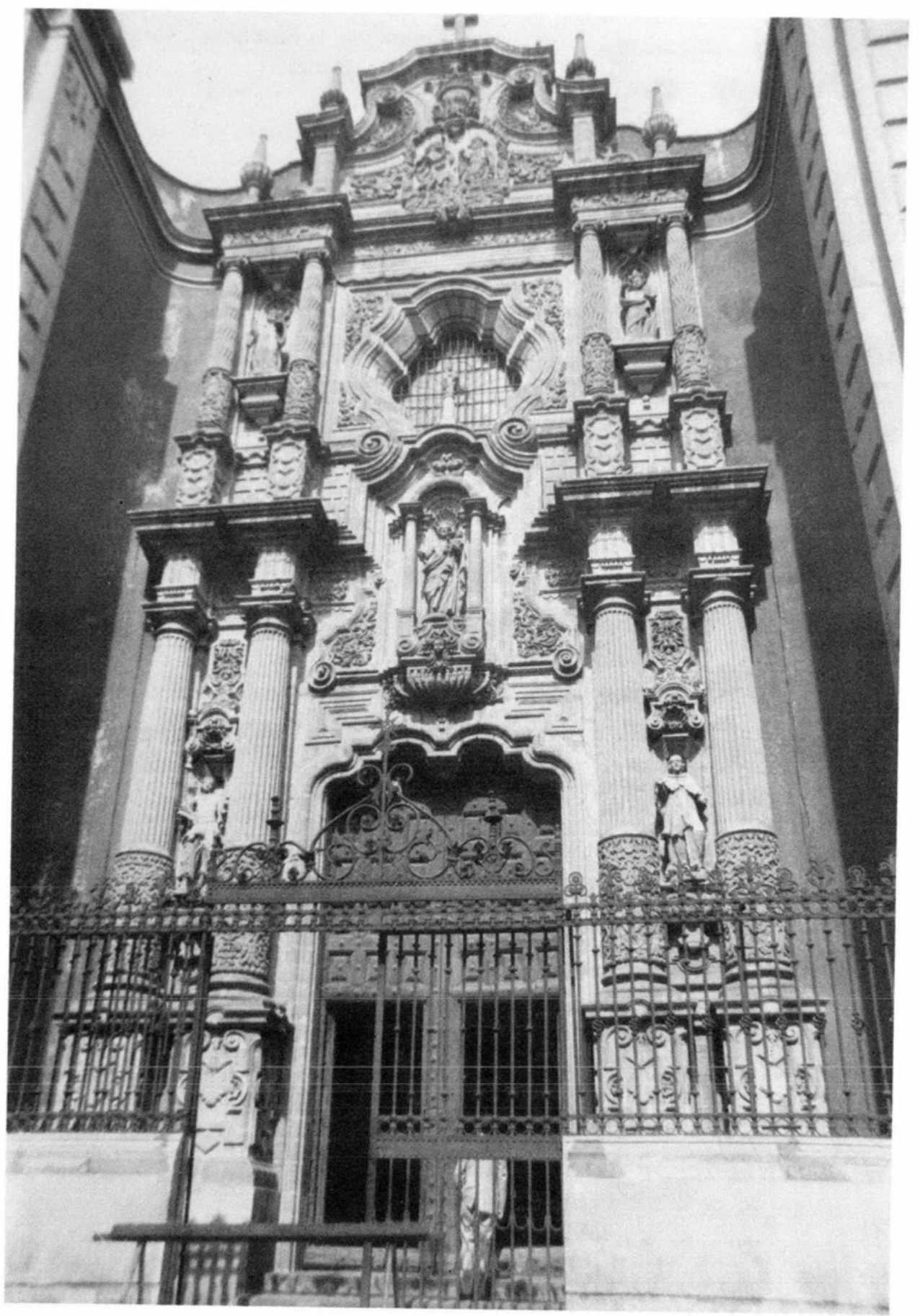

4. Templo de la Enseñanza. Ciudad de México. Portada. 


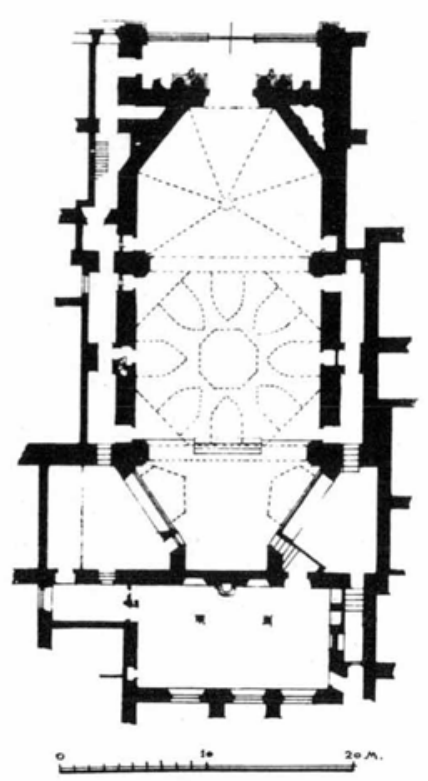

5. Templo de la Enseñanza. Ciudad de México. Planta.

6. Hospital de Belén de Guadalajara. Planta.

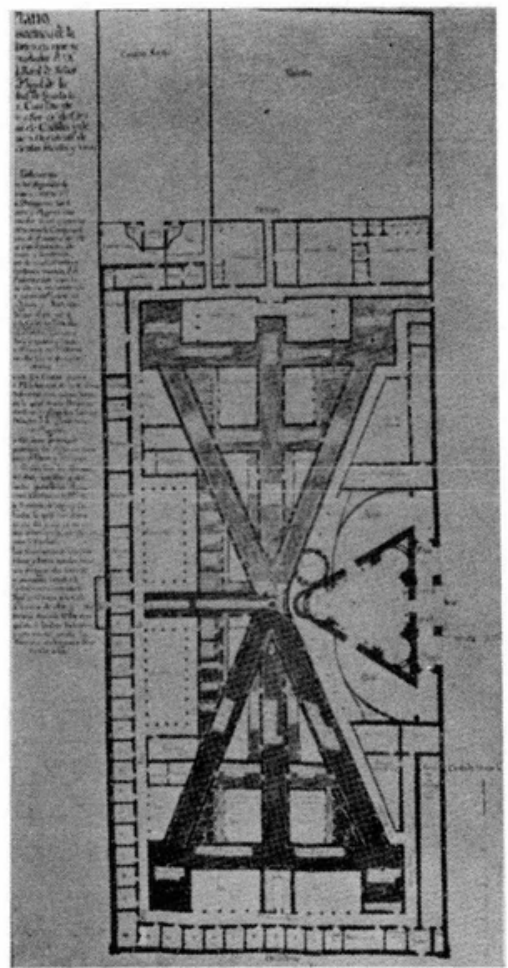


realizaciones artísticas...", ${ }^{50}$ es decir, todo, y en consecuencia, pretendieron un cambio radical que culminó con la Independecia.

De esta manera, para Manrique es el neoclásico el estilo artístico al que

...hay que identificar con la actitud ilustrada general.... la de negar de base los valores barrocos, se dieran éstos en la modalidad estípite o en la modalidad neóstila; no se trataba de enmendar más o menos un camino desviado, sino de borrar todo rastro de aquella pesadilla monstruosa, de aquella fútil vanagloria.... Este es el sentido de los ataques verbales y de la destrucción práctica del barroco ${ }^{51}$

En mi opinión, si bien esta idea es cierta, también lo es el hecho de que en una sociedad, compleja por definición, no podían darse solamente dos posturas opuestas: la barroca, defensora de los valores criollos, y la neoclásica, representativa de la modernidad ilustrada.

Desde mi punto de vista, si podemos aceptar que el neoclásico mexicano conservó mucho del espíritu barroco, podemos también conceder que algunos artistas, por barrocos que fueran, pudieron tener la inquietud y el interés suficiente por las ideas ilustradas que llegaron a la Nueva España y las pusieron en práctica, tal como vimos en el apartado antecedente.

El neóstilo es barroco, pero, por las razones que se analizaron, se apartó del barroquismo tradicional novohispano, de su forma de entenderlo y convertirlo en obra. Por ello, coincido con Jorge Alberto Manrique en considerarlo una modalidad, con características particulares, eclécticas si se quiere, pero en la que ciertamente se percibe una "conciencia nueva" del quehacer barroco. Sólo que, en mi opinión, en tañto "consciente", es racional, y en tanto "nueva" no podía ser otra que la novedad de aquel momento, es decir, la ilustrada.

El sentido de revisión del neóstilo tiene mucho que ver con el de los "recuentos o inventarios" que tanto importaron a los ilustrados en dos sentidos: mostrar el valor universal de lo propio y analizar las posibilidades de avance a partir de lo ya logrado. Quizá sea mucho concederle al neóstilo, pero estoy de acuerdo con juana Gutiérrez cuando afirma que la revisión que se presenta en esa modalidad "...corresponde a una forma de pensamiento enciclopédico típico del momento ilustrado...". ${ }^{52}$

El nuevo sentido barroco que el neóstilo dio a sus obras fue también el producto de un análisis de todas las formas, elementos y artificios propios

\footnotetext{
50 Ibidem, p. 183 .

${ }^{51}$ Ibidem, p. 186

${ }^{52}$ Juana Gutiérrez: op cit
} 
de la arquitectura barroca novohispana y su resultado puede ser visto desde dos ángulos: el de experimentación y el de análisis respecto a la forma correcta de edificar una obra barroca (como en el caso de las columnas salomónicas analizadas).

En ese mismo sentido de corrección y de experimentación hacia algo nuevo veo yo las plantas y composiciones barrocas de las portadas que aparecieron en el neóstilo. Ya no fue suficiente dotar de riqueza y movimiento a un espacio a base de retablos y adornos; en cambio, fue necesario revisar los tratados y, de un modo bien pensado, realizar estructuras realmente barrocas con toda la corrección posible.

El punto de discusión sería cómo entender que, si es ilustrado, el neóstilo utilizara formas barrocas, o cómo calificar de ilustrada a una modalidad que pretendió ser más barroca que ninguna. En opinión de Juana Gutiérrez, lo que ocurre es que el neóstilo parece ser hijo de lo que Elías Trabulse llama "Ilustración espontánea", que por espontánea "...tiene todavía que usar un lenguaje ajeno ya que todavía no ha creado el suyo propio...". ${ }^{53}$

En lo personal, pienso que el neóstilo fue la manera local en que los artistas novohispanos interpretaron las ideas ilustradas procedentes del exterior, pero creo también que el neóstilo es en símismo un nuevo lenguaje, el lenguaje que vino a dar forma plástica, arquitectónica, a las ideas de los maestros que pretendieron reformar sus Ordenanzas y a las del autor del tratado de Architectura Mecanica, por eso es barroco: el neóstilo revisó la tradición propia y a partir de ella puso en práctica las ideas ilustradas. Podríamos decir que es la otra cara de la Ilustración en Nueva España, el otro punto de vista. Ese lenguaje puede entenderse con base en lo expuesto por Antonio Bonet Correa acerca del hospital de Belén de Guadalajara.

$\mathrm{El}$ afán de racionalismo de los últimos barrocos, que confundían lo imaginativo y lo retórico con lo útil, la belleza con lo formal y lo cómodo, intentando unir contrarios, que para ellos pertenecían a un complejo sistema de analogías, puede explicar el adoptar utópicamente una planta de tan complicada realización. Para comprenderlo hay que analizar este tipo de edificios que creían inspirado en la arquitectura romana imperial, en especial la del siglo III, dentro de las categorías barrocas en las que la razón intentaba romper las barreras que diferencian lo verdadero de lo verosimil ${ }^{54}$

\footnotetext{
${ }^{53}$ Juana Gutiérrez: "Las transformaciones del barroco (1720-1785)", inédito Agradezco a la autora el haberme facilitado un ejemplar del maquinuscrito para realizar esta ponencia Apud: Elías Trabulse.

${ }^{54}$ Antonio Bonet Correa: "El hospital de Belén de Guadalajara (México), y los edificios de planta estrellada", en Archivo español de arte, Instituto Diego Velázquez, Consejo Superior de Investigaciones Científicas, t. XL, número 157 (Madrid, 1967), p. 18.
} 
En conclusión, como bien afirma Jorge Alberto Manrique, el neóstilo constituye "la última carta del barroco novohispano", consciente y nuevo, pero va más allá de lo que el propio creador del término consideró, va más allá de una defensa apologética del barroco. Llegó tan lejos como el neoclásico, pero en otro sentido, para convertirse también en la "primera carta de nuestra Ilustración". 